\title{
CYP46A1 Activation By Low-Dose Efavirenz Enhances Brain Cholesterol Metabolism In Subjects With Mild Cognitive Impairment Due To Alzheimer's Disease
}

\author{
Alan J. Lerner \\ University Hospitals Cleveland Medical Center \\ Steven E. Arnold \\ Massachusetts General Hospital \\ Erin Maxfield \\ Case Western Reserve University \\ Aaron Koenig \\ Massachusetts General Hospital \\ Maria E. Toth \\ University Hospitals Cleveland Medical Center \\ Brooke Fortin \\ Massachusetts General Hospital \\ Natalia Mast \\ Case Western Reserve University \\ Bianca A. Trombetta \\ Massachusetts General Hospital \\ John Denker \\ Case Western Reserve University \\ Andrew A. Pieper \\ University Hospitals Cleveland Medical Center \\ Curtis Tatsuoka \\ Case Western Reserve University \\ Sangeetha Raghupathy \\ Case Western Reserve University \\ Irina A. Pikuleva ( $\square$ iap8@case.edu ) \\ Case Western Reserve University
}

Research Article 
Keywords: CYP46A1, efavirenz, Alzheimer's disease, 24-hydroxycholesterol, stable isotope labeling kinetics

Posted Date: February 14th, 2022

DOI: https://doi.org/10.21203/rs.3.rs-1348328/v1

License: (c) (i) This work is licensed under a Creative Commons Attribution 4.0 International License. Read Full License 


\section{Abstract}

Background: Efavirenz is an anti-HIV drug, and cytochrome P450 46A1 (CYP46A1) is a CNS-specific enzyme that metabolizes cholesterol to 24-hydroxycholesterol $(24 \mathrm{HC})$. We have previously shown that allosteric CYP46A1 activation by low-dose efavirenz in a transgenic mouse model of Alzheimer's disease (AD) enhanced both cholesterol elimination and turnover in the brain and improved animal performance in memory tests. Here, we sought to determine whether CYP46A1 could be similarly activated by a lowdose efavirenz in human subjects.

Methods: This pilot study enrolled 5 subjects with mild cognitive impairment due to AD. Participants were randomized to placebo $(n=1)$ or two daily efavirenz doses (50 mg and $200 \mathrm{mg}, \mathrm{n}=2$ for each) for 20 weeks and evaluated for safety and CYP46A1 target engagement (plasma 24HC levels). A longitudinal mixed model was used to ascertain statistical significance of target engagement. We also measured $24 \mathrm{HC}$ in CSF and conducted a unique stable isotope labeling kinetics (SILK) study with deuterated water to directly measure CYP46A1 activity changes in the brain.

Results: In all subjects receiving efavirenz, there was a statistically significant increase $(P £ 0.001)$ in the levels of plasma $24 \mathrm{HC}$. The levels of $24 \mathrm{HC}$ in the CSF of subjects on the $200 \mathrm{mg}$-dose of efavirenz were also increased. Target engagement was further supported by the labeling kinetics of $24 \mathrm{HC}$ by deuterated water in the SILK study. There were no serious adverse effects in any subjects.

Conclusions: Our findings provide evidence of efavirenz target engagement in human subjects with AD. This supports pursuit of a larger trial for further determination and confirmation of the efavirenz dose that exerts maximal enzyme activation, as well as evaluation of this drug effects on AD biomarkers and clinical symptomatology.

\section{Trial registration: ClinicalTrials.gov NCT03706885.}

\section{Background}

Alzheimer's disease (AD) is the most common cause of dementia [1], and it is well recognized that metabolic factors are major drivers of the disease. The involvement of cholesterol in AD pathogenesis is exemplified by APOE, the major cholesterol transport protein in the CNS, and by high prevalence of the APOE e4 allele in patients with late-onset AD [2]. In addition, lipid raft cholesterol modulates the processing of amyloid precursor protein into amyloid $b(A b)$ peptides, a hallmark of $A D$ [3-5], and multiple studies support the importance of cholesterol intake and serum cholesterol levels in $A D[6,7]$. Herein, we report on the novel use of low-dose efavirenz (EFV), a non-nucleoside reverse transcriptase inhibitor given in higher doses to treat human immunodeficiency virus (HIV) infection. We show that low-dose EFV enhances cholesterol elimination from the CNS in subjects with mild cognitive impairment (MCl) due to AD. 
The human brain, which contains approximately $25 \%$ of the body's total unesterified cholesterol [8], is separated from the systemic circulation by the blood-brain barrier, which is impermeable to cholesterol. Hence, brain cholesterol is synthesized locally, with elimination mainly $(75 \%)$ an enzymatic process via conversion to 24-hydroxycholesterol (24HC) by cytochrome P450 46A1 (CYP46A1) [9-11]. Under normal conditions, human CYP46A1 is a CNS-specific neuronal enzyme $[12,13]$ controlling not only the major pathway of the brain cholesterol elimination [11] but also brain cholesterol turnover; with tight coupling between cholesterol 24-hydoxylation and cholesterol biosynthesis to maintain homeostatic levels of brain cholesterol [14]. In AD, however, there is ectopic CYP46A1 expression in astrocytes and decreased expression in neurons $[12,13]$. Nevertheless, CYP46A1 still controls brain cholesterol turnover in this disease $[15,16]$.

Once $24 \mathrm{HC}$ is formed, it rapidly diffuses out of the brain and reaches either the systemic circulation (99\%) or the cerebrospinal fluid (CSF, 1\%), with subsequent delivery to the liver where it undergoes further biotransformation $[17,18]$. Accordingly, $24 \mathrm{HC}$ in the systemic circulation serves as a marker for brain activity of CYP46A1 [19]. Systemic levels of 24HC are also affected by liver function (or the ratio between the brain weight and liver volume), body surface area, disease state, inflammation, dysfunction of the blood-brain barrier, and medications that alter whole body and brain cholesterol maintenance $[19,20]$.

In preclinical mouse studies, we discovered that CYP46A1 could be activated by low-dose $(0.1 \mathrm{mg} / \mathrm{day} / \mathrm{kg}$ of body weight) EFV, while higher doses (>0.22 mg/day $/ \mathrm{kg}$ of body weight) of EFV inhibited CYP46A1 [21]. Moreover, CYP46A1 activation by EFV improved cognitive performance in 5XFAD mice, a model of $A D$ with transgenic expression of human mutant amyloid precursor protein and human mutant presenilin 1 [22]. The effect of EFV on brain Ab load was treatment-specific and dependent on animal age and the presence of $A b$ plaques at the initiation of treatment $[23,24]$. Other treatment-specific EFV effects included changes in astrocyte and microglia activation, and expression of essential synaptic proteins [24, 25]. Mechanistically, CYP46A1 activation by EFV was established to alter sterol flux through the plasma membranes and thereby alter their physico-chemical properties. The latter was found to affect membrane-dependent events, such as synaptic transmission as well as phosphorylation of cytoskeletal and other proteins [26, 27]. In addition, increased sterol flux was shown to have a normalizing effect on total brain acetyl-CoA content in 5XFAD mice, and to increase the energetic state of their brain mitochondria [27]. A model of how one enzyme can control multiple and apparently unrelated processes in the brain was thus proposed $[28,29]$.

The $0.1 \mathrm{mg} /$ day $/ \mathrm{kg}$ of body weight EFV dose activating CYP46A1 in mice approximately compares to a daily $3 \mathrm{mg}$ EFV dose, assuming a $30 \mathrm{~g}$-animal. This dose is much lower than that approved for human use to keep HIV load low (600 mg of EFV per day). Accordingly, we hypothesized that low EFV doses could be used to safely activate CYP46A1 in human subjects. Therefore, we conducted a proof-ofconcept clinical research study of 50- and 200-mg daily EFV doses in patients with AD (Efavirenz for Patients with Alzheimer's Disease or EPAD, ClinicalTrials.gov: NCT03706885).

\section{Methods}




\section{Study Design}

This was an exploratory randomized, double-blind placebo-controlled study with primary objectives to: 1) ascertain if $50 \mathrm{mg}$ and $200 \mathrm{mg}$ daily EFV doses engage CYP46A1 to affect human brain cholesterol metabolism as reflected by changes in plasma $24 \mathrm{HC}$ levels by at least $30 \%$ (an arbitrary cut off); and 2) confirm the safety and tolerability of $50 \mathrm{mg}$ and $200 \mathrm{mg}$ daily doses of EFV in older adults with cognitive impairment. A secondary objective was to precisely measure the effect of EFV on CYP46A1 activity and CNS-cholesterol turnover via stable isotope labeling kinetics (SILK). The tertiary objective was to investigate through post-hoc analysis whether APOE isoforms and single nucleotide polymorphisms (SNP) in CYP46A1 and CYP2B6 (the latter encodes an enzyme that metabolizes EFV) affect study participant response to low dose EFV.

\section{Participant Recruitment and Randomization}

The study was conducted at two clinical sites: (1) the University Hospitals Cleveland Medical Center's (UHCMC) Brain Health and Memory Center and the Memory Disorders Clinic in Cleveland, $\mathrm{OH}$, and (2) the Alzheimer's Clinical \& Translational Research Unit at Massachusetts General Hospital (MGH) in Boston, MA.

Principal inclusion criteria for patient recruitment were as follows: age of 55-85; male or female; diagnosed with $\mathrm{MCl}$ or early dementia due to $\mathrm{AD}$ as defined by history of complaint of cognitive decline, a Mini-Mental State Exam score between 16 and 30, and a Clinical Dementia Rating global score between 0.5-1 [30, 31]. Principal exclusion criteria included CNS disease other than suspected prodromal or early $A D$, other systemic abnormalities or medications that might contribute to cognitive dysfunction, and other medications that are known to significantly alter cholesterol synthesis or metabolism in the brain, including brain penetrant statins. Detailed inclusion and exclusion criteria are presented in Supplemental Methods.

Randomization was stratified by clinical site, age (less than 70 years old vs 70 or greater), and gender. Double blinding was ensured by over-encapsulation of the commercially available $50 \mathrm{mg}$ and $200 \mathrm{mg}$ capsules of Sustiva (Bristol Myers Squibb) and by manufacturing placebo capsules by a compounding pharmacy (Lee Silsby Pharmacy in Cleveland, $\mathrm{OH}$ ).

\section{Study Measures}

A complete list of evaluations conducted at screening, baseline, and study visits is summarized in Supplemental Table 1. All evaluations were the same at both clinical sites, except the participant at MGH underwent an additional stable isotope labeling kinetics (SILK) study using the protocol of deuterated water $\left(\mathrm{D}_{2} \mathrm{O}\right)$ administration [32] that we adapted to measure deuterium water incorporation in newly synthesized and metabolized cholesterol. This participant took $70 \mathrm{ml}$ of $70 \%$ deuterated $\mathrm{D}_{2} \mathrm{O}$ (SigmaAldrich) by mouth three times a day (with at least a 3-hour interval) for 7 consecutive days. $\mathrm{D}_{2} \mathrm{O}$ was administered twice: the first time during the week after the baseline visit and the second time during week 
16 of the study. Fasting blood was drawn on days $7,9,14$, and 21 after initiation of the $\mathrm{D}_{2} \mathrm{O}$ administration, as well as at weeks $4,8,12,16,20$, and 22 during in-clinic visits. Plasma was obtained from the blood and used for measurements of deuterium $\left({ }^{2} \mathrm{H}\right)$ incorporation into $24 \mathrm{HC}$ or ${ }^{2} \mathrm{H} 24 \mathrm{HC}$ enrichment. Plasma processing was as described below for unlabeled 24HC, except the deuterated internal standard was omitted. Deuterated forms of $24 \mathrm{HC}$ were monitored by gas chromatography-mass spectrometry (GC-MS) in the SIM (selected ion monitoring) mode by peaks at $m / z 504,505$, and 506 for one, two, and three deuterium atom incorporation into $24 \mathrm{HC}$, respectively. Unlabeled $24 \mathrm{HC}$ was monitored by the peak at $m / z 503$, which represented the sterol molecular ion. The $24 \mathrm{HC}$ ion peaks at $\mathrm{m} / \mathrm{z} 503 \AA 506$ were then corrected for the background natural abundance of the $24 \mathrm{HC}$ mass isotopomers determined from the plasma samples of subjects not given $\mathrm{D}_{2} \mathrm{O}$. Total ${ }^{2} \mathrm{H}$ incorporation per $24 \mathrm{HC}$ molecule was then calculated as a \% from the sum of unlabeled and deuterated forms of $24 \mathrm{HC}$ as described [33]. To normalize deuterium labeling of plasma $24 \mathrm{HC},{ }^{2} \mathrm{H}$ incorporation into body water was measured as described [34] by plasma isotopic exchange with acetone.

Unlabeled cholesterol and 24HC were quantified by isotope-dilution GC-MS [35, 36] using a mixture of deuterated $\left[25,26,26,26,27,27,27-{ }^{2} \mathrm{H}_{7}\right]$ cholesterol and deuterated $\left[25,26,26,26,27,27,27-{ }^{2} \mathrm{H}_{7}\right] 24 \mathrm{HC}$ that served as internal standards. Sample processing was as described [35] with the sample volumes and amounts of internal standards being $0.01 \mathrm{ml}$ and $25 \mathrm{nmol}$ of deuterated cholesterol for measurement of total plasma cholesterol; $0.5 \mathrm{ml}$ and $0.1 \mathrm{nmol}$ of deuterated $24 \mathrm{HC}$ for measurement of total plasma $24 \mathrm{HC}$; and $1 \mathrm{ml}$ for total sterol measurements in CSF, which required $2.5 \mathrm{nmol}$ of deuterated cholesterol and $0.001 \mathrm{nmol}$ of deuterated 24HC. Samples were mixed with $3 \mathrm{ml}$ of $1.0 \mathrm{~N} \mathrm{KOH}$ in $70 \%$ aqueous ethanol and saponified at $37^{\circ} \mathrm{C}$ for $2 \mathrm{hrs}$. Then, 10 drops of concentrated $\mathrm{HCl}, 5 \mathrm{ml}$ of chloroform, and $1.5 \mathrm{ml}$ of $0.9 \% \mathrm{NaCl}$ in water were added, and the mixture was vortexed and centrifuged at $1,000 \mathrm{~g}$ for $5 \mathrm{~min}$. The lower organic phase was transferred to a new glass tube, and the chloroform extraction was repeated. The organic phases from the two extractions were combined and dried in a SpeedVac. For cholesterol quantification in plasma, dried lipid extracts were trimethylsilated with $0.2 \mathrm{ml}$ of bis-(trimethylsilyl) trifluoroacetamide/trimethylchlorosilane at $60^{\circ} \mathrm{C}$ for 10 minutes and analyzed by GC-MS as described [35]. For cholesterol measurements in CSF, as well as 24HC measurements in plasma and CSF, dried lipid extracts were dissolved in $0.3 \mathrm{ml}$ of methanol and loaded onto a Varian C18 column (1000 mg; Varian Inc., Lake Forest, $\mathrm{CA}$ ) equilibrated with $5 \mathrm{ml} \mathrm{CH}{ }_{3} \mathrm{OH} / \mathrm{CH}_{3} \mathrm{CN} / \mathrm{H}_{2} \mathrm{O}(40: 40: 20$, vol/vol/vol). The columns were washed with $20 \mathrm{ml} \mathrm{CH} 3 \mathrm{OH} / \mathrm{CH}_{3} \mathrm{CN} / \mathrm{H}_{2} \mathrm{O}$ (82:12:6, vol/vol/vol), resulting in elution of the oxysterol fraction containing $24 \mathrm{HC}$. Cholesterol was eluted by subsequently washing the column with 20 $\mathrm{ml}$ of methanol. All eluates were evaporated to dryness followed by trimethylsilation as described above for analysis by GC-MS. The following ions $(\mathrm{m} / \mathrm{z}$ ) were monitored in the SIM mode: 368 (cholesterol), 375 (deuterated cholesterol), $145(24 \mathrm{HC}$ ), and 152 (deuterated $24 \mathrm{HC}$ ). For quantification, calibration curves were generated using a fixed concentration of the internal standard and varying concentrations of the unlabeled sterol. Each sample was analyzed once after three randomly selected samples were used to determine the coefficient of variation (CV) between three independent sample processing events. The CVs 
were $0.4 \%$ for plasma cholesterol, $4.5 \%$ for plasma $24 \mathrm{HC}, 4.4 \%$ for CSF cholesterol, and $2.2 \%$ for CSF $24 \mathrm{HC}$.

CSF $A b 42$ and 40 peptides ( $A b_{42}$ and $A b_{40}$, respectively), total tau, and phosphor-tau ${ }^{181}$ were measured by the Biomarker Core at the Massachusetts Alzheimer's Disease Research Center using commercial ELISA kits (EUROIMMUN, Lübeck, Germany), according to manufacturer instructions. The short-term intervisit CVs for these $A D$ markers were normally up to $5 \%$.

Genotyping for the APOE isoform status (e2, e4 or e4) and single nucleotide polymorphisms in CYP46A1 (rs754203) and CYP2B6 (rs3745274) was conducted by the Molecular Biology and Genotyping Core of the Visual Sciences Research Center at Case Western Reserve University (Cleveland, $\mathrm{OH}$ ).

\section{Study Approval}

This study was approved by the Institutional Review Board at the UHCMC (the protocol \# 09-17-26) for the Cleveland site and Partners Human Research Committee (protocol \# 2018P000615/PHS) for the Boston site.

\section{Statistical Analysis}

A longitudinal mixed model was used to ascertain statistical significance of target (CYP46A1) engagement. Baseline, 4, 8, 12, 16, and 20-week plasma $24 \mathrm{HC}$ levels were included in the analysis of the four subjects who received EFV. For one subject, only baseline, 4-, and 8-week plasma 24HC levels were observed, as the subject withdrew from the study. There also was one missing 4-week measurement in another subject. These missing data were implicitly imputed in the mixed model fit. We conducted a twosided test with Type I error of 0.05 . The null hypothesis was that the slope parameter associating $24 \mathrm{HC}$ level with a continuous time variable (weeks) was equal to 0 . We did not conduct a two-group comparison between subjects that received EFV vs placebo, as there was only one subject who completed the study in the placebo group.

\section{Results}

\section{Participant Characteristics}

Five subjects (one at MGH site and four at UHCMC site, described in Table 1) were enrolled in the study (CONSORT Supplemental Fig. 1). One participant was randomized to receive placebo, two received $50 \mathrm{mg}$ of EFV per day, and two received $200 \mathrm{mg}$ of EFV per day. Of the five participants, four completed the study, and one (502-207, assigned to a $50 \mathrm{mg}$ /day dose) withdrew from the study after week 8 due to a diffuse maculopapular rash, a known common occurrence with EFV. The four completers had at least one APOE e4 allele, and the participant on placebo (502-204) was also heterozygous for CYP46A1 rs754203. This SNP has been found to be associated with $A D$ in some but not all linkage studies [37]. Of the four study subjects who received EFV, one (502-201) was heterozygous and one (501-110) was homozygous 
for CYP2B6 rs3745274, a SNP associated with impaired EFV metabolism and thus high plasma EFV levels [38].

\section{Study Primary Outcomes: Target Engagement and Safety}

At week 20, plasma $24 \mathrm{HC}$ levels were increased relative to baseline levels in the three participants on EFV who completed the study: by $6 \%$ in $502-201 ; 14 \%$ in $501-110$; and $29 \%$ in $502-202$ (Fig. 1). However, at week 22, after EFV had been discontinued for 2 weeks, plasma $24 \mathrm{HC}$ levels were decreased relative to week 20 in these participants, consistent with the activating effect of EFV on CYP46A1. In addition, the participant on EFV who terminated early (502-207) also had an increase in plasma $24 \mathrm{HC}$ content (by $73 \%$ at week 8). The analysis of changes in plasma $24 \mathrm{HC}$ levels of all four participants on EFV with a linear mixed model of time (weeks) (also included participant-level random intercepts and heterogeneous variances per time period) revealed a positive association $(P<0.001)$, with slope parameter estimate of 0.828 , and $95 \%$ confidence interval of $(0.630,1.025)$.

In the participant on placebo (502-204), who was taking $10 \mathrm{mg}$ /day atorvastatin as well, serum $24 \mathrm{HC}$ levels were decreased at week 20 relative to baseline levels and also at week 22 relative to week 20 (Fig. 1).

Similar to the increases in the plasma, CSF $24 \mathrm{HC}$ levels at week $20 \mathrm{vs}$ baseline were also increased in the two participants on daily 200 mg EFV, by 14\% in 501-110 and 12\% in 502-202 (Fig. 1).

In terms of safety, both EFV doses were overall well tolerated by the study participants. There were no serious adverse events or other adverse events, such as neuropsychiatric symptoms known to occur with a daily $600 \mathrm{mg}$ EFV dose in HIV [38, 39]. As noted above, one participant on a daily $50 \mathrm{mg}$ EFV dose withdrew from the study due to diffuse rash felt to be consistent with a medication induced reaction.

\section{Study Secondary Outcome: Target Engagement in SILK}

A unique feature of the brain, namely almost exclusive cholesterol biosynthesis in situ and mostly enzymatic elimination via CYP46A1-catalyzed 24-hydroxylation $[8,10]$, served as the rationale for the SILK study, in which we investigated whether we could directly monitor CYP46A1 activity in the brain and brain cholesterol turnover. After oral consumption, $\mathrm{D}_{2} \mathrm{O}$ appears in the blood within 1-2 hours [40,41] and equilibrates within minutes with intracellular water across different organs [42]. We reasoned that deuterium atoms from $\mathrm{D}_{2} \mathrm{O}$ could then be incorporated into cerebral cholesterol during in situ biosynthesis and remain in the newly synthesized cholesterol during its subsequent conversion to $24 \mathrm{HC}$ and sterol diffusion to the systemic circulation. If so, plasma $24 \mathrm{HC}$ should be enriched with ${ }^{2} \mathrm{H}$, and the extent of this enrichment should reflect CYP46A1 activity and the rate of cerebral cholesterol turnover.

One participant (501-110, on a daily $200 \mathrm{mg}$ EFV dose) underwent the SILK study. $\mathrm{D}_{2} \mathrm{O}$ ingestion by this participant led to plasma $24 \mathrm{HC}$ enrichment with up to three deuterium atoms $\left({ }^{2} \mathrm{H}\right.$, peaks at $m / z 504,505$, and 506, respectively, Fig. $1 \mathrm{~A}$ ) as compared to the naturally abundant mass isotopomers of $24 \mathrm{HC}$ 
measured at the baseline visit before $\mathrm{D}_{2} \mathrm{O}$ ingestion. Also, the ${ }^{2} \mathrm{H}$ incorporation into plasma $24 \mathrm{HC}$ was low (up to $4.8 \%$ ) but detectable during the first half of the SILK study (weeks 1-10), yet it was increased to $35 \%$ during weeks $10-20$ of the study (Fig. 1B). Then, at week 22 after a two-week wash out period, total $24 \mathrm{HC}$ deuteration decreased by $10 \%$, despite the fact that the deuteration extent of the body water remaining the same (Fig. 1B inset). To account for the differences in the body water ${ }^{2} \mathrm{H}$ enrichment during the study, we calculated the areas under the curve (AUC) for $24 \mathrm{HC}$ and body water ${ }^{2} \mathrm{H}$ enrichments during the first and last 8 weeks of the study. The AUC data for the plasma $24 \mathrm{HC}$ deuteration were then divided by the corresponding AUC data for the body water deuteration. The resulting values were 8.0/1.6=4.9 and $72.8 / 5.7=12.7$ for the first and last 8 weeks of the study, respectively. The difference in the AUC ratios for weeks 1-8 and 12-20 was more than 2.5-fold, suggesting that EFV activated CYP46A1 in the study participant and likely also enhanced brain cholesterol turnover.

\section{Other Study Measures}

These measures included changes in $A D$ markers in CSF $\left(A b_{40}\right.$ and $A b_{42}$ peptides; total tau and phosphor$\operatorname{tau}^{181}$ ) as well as in the Montreal Cognitive Assessment (MoCA) scores conducted as a part of safety evaluations (Fig. 1). There were no evident changes in the AD markers, nor did these correlate with plasma $24 \mathrm{HC}$ levels. MoCA scores did not change in one subject on placebo (502-204), but were increased by 3 points in both subjects on a daily $50 \mathrm{mg}$ EFV dose (502-201) and decreased by 3 and 2 points in the subjects on daily $200 \mathrm{mg}$ EFV dose (501-110 and 502-202, respectively).

\section{Discussion}

We investigated whether a 20-week daily treatment with low-dose EFV could activate CYP46A1 in humans. Despite our previous studies of EFV in mice [21, 23, 24], we could not extrapolate these treatments to a clinical trial because extant data indicate that inter-species differences may be large for the rates of brain cholesterol synthesis and metabolism. Indeed, bulk cholesterol turnover has been estimated at 9.1 years or $0.03 \%$ per day in humans [43] vs 0.7 years or $0.4 \%$ per day in mice [8]. However, in metabolically active brain neurons of mice, cholesterol turnover was suggested to be very high, namely $20-30 \%$ per day $[43,44]$. Hence, for proof-of-principle target engagement, we evaluated commercially available EFV doses and selected 20 weeks as the treatment time, reasoning that this should be sufficient if human brain neurons metabolize cholesterol as actively as mouse brain neurons.

While a small study, we nonetheless show that EFV treatment engages and activates CYP46A1 in the human brain. First, by the end of the treatment period, all participants on EFV had a statistically significant increase in plasma $24 \mathrm{HC}$ levels, which then decreased after discontinuation of EFV treatment (Fig. 1). Second, the results of the SILK study were consistent with CYP46A1 activation by EFV with a 2.5fold increase in the normalized deuterium plasma $24 \mathrm{HC}$ enrichment during the last 8 weeks of the study $v s$ the first 8 weeks of the study (Fig. 2). Third, in addition to the plasma, increases in $24 \mathrm{HC}$ levels were observed in CSF (Fig. 1) where $24 \mathrm{HC}$ also diffuses from the brain $[17,18]$. Collectively, these three lines of evidence show that in the brains of participants with $\mathrm{MCl}$ due to $\mathrm{AD}$, EFV activates CYP46A1 at both 50 
$\mathrm{mg} /$ day and $200 \mathrm{mg} /$ day, and that a 20-week treatment is sufficient to observe this activation. Apparently, cholesterol turnover in the metabolically active brain neurons in humans is much higher than $0.03 \%$ per day, an important practical finding for future studies of CYP46A1 activation in humans. Thus, our data prompt larger clinical studies to further characterize CYP46A1 activation by EFV, including identification of the maximally effective dose for $A D$ patients and additional insights into possible clinical efficacy in this population.

Several additional points are worth discussion. The first is a potential statin effect on plasma $24 \mathrm{HC}$ levels. Only $6 \%$ and $3 \%$ increases in plasma and CSF $24 \mathrm{HC}$ levels, respectively, were in participant 502201 , who was on a $40 \mathrm{mg} /$ day dose of atorvastatin. This atorvastatin dose is known to decrease plasma $24 \mathrm{HC}$ levels by $25 \%$ after 2 months of treatment [45]. Accordingly, it is possible that a minimal EFV effect on plasma and CSF $24 \mathrm{HC}$ in participant $502-201$ is due to a confounding brain $24 \mathrm{HC}$ decrease because of atorvastatin treatment. This explanation is supported by $19 \%$ and $4 \%$ decreases in plasma and CSF 24HC levels, respectively, in participant 502-204 who was also taking atorvastatin but at a 10 $\mathrm{mg} /$ day dose and was on placebo. Apparently, this atorvastatin dose was not sufficient to stabilize the participant's plasma cholesterol levels, which increased almost twice by the end of the study (Fig. 1).

Participant 501-110 was homozygous for the activity-decreasing rs3745274 SNP in CYP2B6, whose carriers are suggested to receive a 3-times lower EFV amount to prevent overdose [46]. This participant had a lower plasma $24 \mathrm{HC}$ increase relative to participant 502-202 who did not carry this SNP (Fig. 1). Thus, to have subjects with comparable EFV doses, genotyping for the rs3745274 SNP in CYP2B6 should be included in future studies.

The administration of $\mathrm{D}_{2} \mathrm{O}$ to humans to trace different small molecules and proteins has been in practice since 1950 [32, 40, 41, 47]. However, we are the first group to apply this approach for measurement of cholesterol 24-hydroxylation in the brain and CYP46A1 activation. We used two $D_{2} \mathrm{O}$ administrations, at the beginning and end of the study, as we were not sure whether body water would still be enriched with ${ }^{2} \mathrm{H}$ at the end of the study, a prerequisite for labeling of newly-synthesized brain cholesterol. Indeed, body water deuteration was not detectable at week 8 of the SILK study (Fig. 2B inset). Hence, the second $\mathrm{D}_{2} \mathrm{O}$ administration at week 16 proved to be useful and was safe: the maximal ${ }^{2} \mathrm{H}$ enrichment of body water was $2.5 \%$, the labeling extent almost ten times lower than that $(20 \%)$ considered as safe in animals [32]. The study ended at week 20, when the ${ }^{2} \mathrm{H}$ enrichment of plasma $24 \mathrm{HC}$ was maximal (Fig. 2B). Therefore, our normalizations of the AUC for plasma $24 \mathrm{HC}$ deuteration to the AUC for total body ${ }^{2} \mathrm{H}$ labeling represent rough estimates only. Nevertheless, they are informative and represent a more direct measure of CYP46A1 activation by EFV (and likely turnover) than plasma 24HC levels. Indeed, in a linear segment of the curve (week 4 to week 8, Fig. 2B), the average rate of plasma $24 \mathrm{HC}$ deuteration was $0.04 \%$ per day, which is comparable to the rate of brain cholesterol turnover $(0.03 \%$ per day) determined previously in humans using a different approach [43].

The primary objective of this study was to assess EFV target engagement. Neurocognitive and neuropsychiatric assessments were not included as drug efficacy outcomes but rather were carried out 
for safety monitoring. No neurocognitive/psychiatric safety signal emerged. Anecdotally, one participant (502-202) reported experiencing new moments of cognitive clarity and endurance during the treatment period.

\section{Limitations}

The major study limitation is a low number of subjects, which was due in part to the COVID-19 pandemic restricting enrollment. Another limitation is enrollment of two subjects taking atorvastatin, which likely decreased the 20-week (and 22-week) plasma 24HC levels in the subject on placebo [45] and could lower the 20-week increase in the plasma $24 \mathrm{HC}$ content in subject on $50 \mathrm{mg}$ daily EFV.

\section{Conclusions}

This pilot study of EFV (50 mg/day and $200 \mathrm{mg} /$ day for 20 weeks) in subjects with $\mathrm{MCl}$ due to $A D$ demonstrates proof-of-concept activation of CYP46A1, which controls cholesterol metabolism and turnover in the brain. A unique SILK protocol using deuterated water was developed to directly measure CYP46A1 activity in the brain. Collectively, the data support further studies of low-dose EFV as a potential therapeutic approach for AD.

\section{List Of Abbreviations}

24HC, 24-hydroxycholesterol; Ab, amyloid b; AD, Alzheimer's disease; AUC, area under the curve; CSF, cerebrospinal; fluid; CV, coefficient of variation; EFV, efavirenz; GC-MS, gas chromatography-mass spectrometry; $\mathrm{D}_{2} \mathrm{O}$, deuterated water; $\mathrm{HIV}$, human immunodeficiency virus $\mathrm{MGH}$, Massachusetts General Hospital; $\mathrm{MCl}$, mild cognitive impairment; SILK, stable isotope labeling kinetics; SNP, single nucleotide polymorphism; UHCMC, the University Hospitals Cleveland Medical Center.

\section{Declarations}

\section{Ethics approval and consent to participate}

The study was approved by institutional review boards of all participating institutions, and written informed consent was obtained from all participants or their guardians according to the Declaration of Helsinki (consent for research).

\section{Consent for publication}

Not applicable.

\section{Availability of data and materials}

All data generated or analyzed during this study are included in this published article [and its supplementary information files]. 


\section{Competing interests}

The authors declare that they have no competing interests.

\section{Funding}

This study was supported in part by the grants GC-2012681 from the Alzheimer's Drug Discovery Foundation and P30 EY011373 from the National Institutes of Health (IAP) as well as a generous financial contribution from Case Western Reserve University. IAP is a Carl F. Asseff Professor of Ophthalmology. AAP was also supported by a grant from the Brockman Foundation, by Elizabeth Ring Mather \& William Gwinn Mather Fund, S. Livingston Samuel Mather Trust, G.R. Lincoln Family Foundation, Wick Foundation, the Leonard Krieger Fund of the Cleveland Foundation, Gordon \& Evie Safran, and Louis Stokes VA Medical Center resources and facilities. AAP and AJL are supported by the Translational Therapeutic Core of the Cleveland Alzheimer's Disease Research Center (NIH/NIA P30 AG062428-01).

\section{Authors' contributions}

AJL, SEA, EM, AK, and IAP designed the study. SR coordinated the study. MET, BF, NM, BAT, and JD collected the data. CT conducted statistical analyses. AJL, SEA, MET, NM, AAP, CT, and IAP analyzed and interpreted the data. All authors contributed to the writing and revisions of the paper and approved the final version.

\section{Acknowledgements}

Not applicable.

\section{References}

1. Winblad B, Amouyel P, Andrieu S, Ballard C, Brayne C, Brodaty H, et al. Defeating Alzheimer's disease and other dementias: a priority for European science and society. The Lancet Neurology. 2016;15(5):455532.

2. Mahley RW, Rall SC, Jr. Apolipoprotein E: far more than a lipid transport protein. Annu Rev Genomics Hum Genet. 2000;1:507-37.

3. Simons M, Keller P, De Strooper B, Beyreuther K, Dotti CG, Simons K. Cholesterol depletion inhibits the generation of beta-amyloid in hippocampal neurons. Proc Natl Acad Sci U S A. 1998;95(11):6460-4.

4. Barrett PJ, Song Y, Van Horn WD, Hustedt EJ, Schafer JM, Hadziselimovic A, et al. The amyloid precursor protein has a flexible transmembrane domain and binds cholesterol. Science. 2012;336(6085):1168-71. 
5. Wang H, Kulas JA, Wang C, Holtzman DM, Ferris HA, Hansen SB. Regulation of beta-amyloid production in neurons by astrocyte-derived cholesterol. Proc Natl Acad Sci U S A. 2021;118(33).

6. Solomon A, Kivipelto M, Wolozin B, Zhou J, Whitmer RA. Midlife serum cholesterol and increased risk of Alzheimer's and vascular dementia three decades later. Dementia and geriatric cognitive disorders. 2009;28(1):75-80.

7. Reitz C. Dyslipidemia and the risk of Alzheimer's disease. Curr Atheroscler Rep. 2013;15(3):307.

8. Dietschy JM, Turley SD. Cholesterol metabolism in the brain. Curr Opin Lipidol. 2001;12(2):105-12.

9. Lutjohann D, Breuer O, Ahlborg G, Nennesmo I, Siden A, Diczfalusy U, et al. Cholesterol homeostasis in human brain: evidence for an age-dependent flux of 24S-hydroxycholesterol from the brain into the circulation. Proc Natl Acad Sci U S A. 1996;93(18):9799-804.

10. Bjorkhem I, Lutjohann D, Diczfalusy U, Stahle L, Ahlborg G, Wahren J. Cholesterol homeostasis in human brain: turnover of 24S-hydroxycholesterol and evidence for a cerebral origin of most of this oxysterol in the circulation. J Lipid Res. 1998;39(8):1594-600.

11. Lund EG, Guileyardo JM, Russell DW. cDNA cloning of cholesterol 24-hydroxylase, a mediator of cholesterol homeostasis in the brain. Proc Natl Acad Sci U S A. 1999;96(13):7238-43.

12. Brown J, 3rd, Theisler C, Silberman S, Magnuson D, Gottardi-Littell N, Lee JM, et al. Differential expression of cholesterol hydroxylases in Alzheimer's disease. J Biol Chem. 2004;279(33):34674-81.

13. Bogdanovic N, Bretillon L, Lund EG, Diczfalusy U, Lannfelt L, Winblad B, et al. On the turnover of brain cholesterol in patients with Alzheimer's disease. Abnormal induction of the cholesterol-catabolic enzyme CYP46 in glial cells. Neurosci Lett. 2001;314(1-2):45-8.

14. Lund EG, Xie C, Kotti T, Turley SD, Dietschy JM, Russell DW. Knockout of the cholesterol 24hydroxylase gene in mice reveals a brain-specific mechanism of cholesterol turnover. $\mathrm{J}$ Biol Chem. 2003;278(25):22980-8.

15. Varma VR, Büşra Lüleci H, Oommen AM, Varma S, Blackshear CT, Griswold ME, et al. Abnormal brain cholesterol homeostasis in Alzheimer's disease-a targeted metabolomic and transcriptomic study. npj Aging and Mechanisms of Disease. 2021;7(1):11.

16. Testa G, Staurenghi E, Zerbinati C, Gargiulo S, Iuliano L, Giaccone G, et al. Changes in brain oxysterols at different stages of Alzheimer's disease: Their involvement in neuroinflammation. Redox Biol. 2016;10:24-33.

17. Bjorkhem I, Andersson U, Ellis E, Alvelius G, Ellegard L, Diczfalusy U, et al. From brain to bile. Evidence that conjugation and omega-hydroxylation are important for elimination of 24Shydroxycholesterol (cerebrosterol) in humans. J Biol Chem. 2001;276(40):37004-10. 
18. Leoni V, Masterman T, Mousavi FS, Wretlind B, Wahlund LO, Diczfalusy U, et al. Diagnostic use of cerebral and extracerebral oxysterols. Clinical chemistry and laboratory medicine : CCLM / FESCC. 2004;42(2):186-91.

19. Bretillon L, Lutjohann D, Stahle L, Widhe T, Bindl L, Eggertsen G, et al. Plasma levels of 24Shydroxycholesterol reflect the balance between cerebral production and hepatic metabolism and are inversely related to body surface. J Lipid Res. 2000;41(5):840-5.

20. Leoni V, Caccia C. 24S-hydroxycholesterol in plasma: a marker of cholesterol turnover in neurodegenerative diseases. Biochimie. 2013;95(3):595-612.

21. Mast N, Li Y, Linger M, Clark M, Wiseman J, Pikuleva IA. Pharmacologic stimulation of cytochrome P450 46A1 and cerebral cholesterol turnover in mice. J Biol Chem. 2014;289(6):3529-38.

22. Oakley H, Cole SL, Logan S, Maus E, Shao P, Craft J, et al. Intraneuronal beta-amyloid aggregates, neurodegeneration, and neuron loss in transgenic mice with five familial Alzheimer's disease mutations: potential factors in amyloid plaque formation. J Neurosci. 2006;26(40):10129-40.

23. Mast N, Saadane A, Valencia-Olvera A, Constans J, Maxfield E, Arakawa H, et al. Cholesterolmetabolizing enzyme cytochrome P450 46A1 as a pharmacologic target for Alzheimer's disease. Neuropharmacology. 2017;123:465-76.

24. Petrov AM, Lam M, Mast N, Moon J, Li Y, Maxfield E, et al. CYP46A1 Activation by Efavirenz Leads to Behavioral Improvement without Significant Changes in Amyloid Plaque Load in the Brain of 5XFAD Mice. Neurotherapeutics : the journal of the American Society for Experimental NeuroTherapeutics. 2019;16(3):710-24.

25. Petrov AM, Mast N, Li Y, Pikuleva IA. The key genes, phosphoproteins, processes, and pathways affected by efavirenz-activated CYP46A1 in the amyloid-decreasing paradigm of efavirenz treatment. FASEB J. 2019;33(8):8782-98.

26. Petrov AM, Mast N, Li Y, Denker J, Pikuleva IA. Brain sterol flux mediated by cytochrome P450 $46 A 1$ affects membrane properties and membrane-dependent processes. Brain Commun. 2020;2(1).

27. Mast N, Petrov AM, Prendergast E, Bederman I, Pikuleva IA. Brain Acetyl-CoA Production and Phosphorylation of Cytoskeletal Proteins Are Targets of CYP46A1 Activity Modulation and Altered Sterol Flux. Neurotherapeutics : the journal of the American Society for Experimental NeuroTherapeutics. 2021.

28. Pikuleva IA. Targeting cytochrome P450 46A1 and brain cholesterol 24-hydroxylation to treat neurodegenerative diseases. Explor Neuroprot Ther. 2021;1(3):Online First-Online First.

29. Pikuleva IA, Cartier N. Cholesterol Hydroxylating Cytochrome P450 46A1: From Mechanisms of Action to Clinical Applications. Front Aging Neurosci. 2021;13(400):696778. 
30. Folstein MF, Folstein SE, McHugh PR. "Mini-mental state". A practical method for grading the cognitive state of patients for the clinician. J Psychiatr Res. 1975;12(3):189-98.

31. Hughes CP, Berg L, Danziger WL, Coben LA, Martin RL. A new clinical scale for the staging of dementia. Br J Psychiatry. 1982;140:566-72.

32. Fanara P, Wong PY, Husted KH, Liu S, Liu VM, Kohlstaedt LA, et al. Cerebrospinal fluid-based kinetic biomarkers of axonal transport in monitoring neurodegeneration. J Clin Invest. 2012;122(9):3159-69.

33. Lee WN, Bassilian S, Guo Z, Schoeller D, Edmond J, Bergner EA, et al. Measurement of fractional lipid synthesis using deuterated water $(2 \mathrm{H} 2 \mathrm{O})$ and mass isotopomer analysis. The American journal of physiology. 1994;266(3 Pt 1):E372-83.

34. Lin JB, Mast N, Bederman IR, Li Y, Brunengraber H, Bjorkhem I, et al. Cholesterol in mouse retina originates primarily from in situ de novo biosynthesis. J Lipid Res. 2016;57(2):258-64.

35. Mast N, Reem R, Bederman I, Huang S, DiPatre PL, Björkhem I, et al. Cholestenoic acid is an important elimination product of cholesterol in the retina: comparison of retinal cholesterol metabolism with that in the brain. Invest Ophthalmol Vis Sci. 2011;52(1):594-603.

36. Dzeletovic S, Breuer O, Lund E, Diczfalusy U. Determination of cholesterol oxidation products in human plasma by isotope dilution-mass spectrometry. Anal Biochem. 1995;225(1):73-80.

37. Li M, Wang W, Li Y, Wang L, Shen X, Tang Z. CYP46A1 intron-2T/C polymorphism and Alzheimer's disease: an updated meta-analysis of 16 studies including 3,960 cases and 3,828 controls. Neurosci Lett. 2013;549:18-23.

38. Apostolova N, Funes HA, Blas-Garcia A, Galindo MJ, Alvarez A, Esplugues JV. Efavirenz and the CNS: what we already know and questions that need to be answered. J Antimicrob Chemother. 2015;70(10):2693-708.

39. Dalwadi DA, Ozuna L, Harvey BH, Viljoen M, Schetz JA. Adverse neuropsychiatric events and recreational use of efavirenz and other HIV-1 antiretroviral drugs. Pharmacol Rev. 2018;70(3):684-711.

40. London IM, Rittenberg D. Deuterium studies in normal man. I. The rate of synthesis of serum cholesterol. II. Measurement of total body water and water absorption. J Biol Chem. 1950;184(2):687-91.

41. Jones PJ, Leitch CA, Li ZC, Connor WE. Human cholesterol synthesis measurement using deuterated water. Theoretical and procedural considerations. Arterioscler Thromb Vasc Biol. 1993;13(2):247-53.

42. Dietschy JM, Spady DK. Measurement of rates of cholesterol synthesis using tritiated water. J Lipid Res. 1984;25(13):1469-76. 
43. Dietschy JM, Turley SD. Thematic review series: brain Lipids. Cholesterol metabolism in the central nervous system during early development and in the mature animal. J Lipid Res. 2004;45(8):1375-97.

44. Dietschy JM. Central nervous system: cholesterol turnover, brain development and neurodegeneration. Biol Chem. 2009;390(4):287-93.

45. Thelen KM, Laaksonen R, Päivä H, Lehtimäki T, Lütjohann D. High-dose statin treatment does not alter plasma marker for brain cholesterol metabolism in patients with moderately elevated plasma cholesterol levels. Journal of clinical pharmacology. 2006;46(7):812-6.

46. Nemaura T, Nhachi C, Masimirembwa C. Impact of gender, weight and CYP2B6 genotype on efavirenz exposure in patients on HIV/AIDS and TB treatment: Implications for individualising therapy. Afr J Pharm Pharmacol. 2012;6(29):2188-93.

47. Jones PJ. Use of deuterated water for measurement of short-term cholesterol synthesis in humans. Can J Physiol Pharmacol. 1990;68(7):955-9.

\section{Table}

Table 1 Demographic and other characteristics of study participants 


\begin{tabular}{|c|c|c|c|c|c|}
\hline Treatment Arm & Placebo & $50 \mathbf{m}$ & EFV & $200 n$ & EFV \\
\hline Characteristic & $502-204$ & $502-201$ & $502-207 *$ & 501-110 & 502-202 \\
\hline Age (years) & 71 & 79 & 86 & 71 & 86 \\
\hline Gender & $\mathrm{M}$ & $\mathrm{M}$ & $\mathrm{F}$ & $\mathrm{F}$ & $\mathrm{M}$ \\
\hline Race & $\mathrm{W}$ & $\mathrm{W}$ & $\mathrm{W}$ & $\mathrm{W}$ & B \\
\hline APOE isoform status & $\varepsilon 3 \varepsilon 4$ & $\varepsilon 3 \varepsilon 4$ & $\varepsilon 3 \varepsilon 3$ & $\varepsilon 3 \varepsilon 4$ & $\varepsilon 4 \varepsilon 4$ \\
\hline CYP46A1 rs754203 (intron-2T $>C$ ) & $+/-$ & $-/-$ & $-/-$ & $-/-$ & $-/-$ \\
\hline CYP2B6 rs $3745274(516 \mathrm{G}>\mathrm{T})$ & $-/-$ & $+/-$ & $-/-$ & $+/+$ & $-/-$ \\
\hline Statin use & $\begin{array}{l}\text { Atorv, } 10 \\
\mathrm{mg} / \text { day }\end{array}$ & $\begin{array}{c}\text { Atorv, } 40 \\
\text { mg/day }\end{array}$ & No & No & No \\
\hline
\end{tabular}

*, withdrew from the study after week 8; M, male; F, female; W, white; B, black; +, present; -, absent; Atorv, atorvastatin.

\section{Figures}

\section{Figure 1}

A summary of major study measures in trial participants. $24 \mathrm{HC}, 24$-hydroxycholesterol; Baseline, baseline visit; Chol, cholesterol; $A \beta_{40}$ and $A \beta_{42}$, amyloid b peptides 40 and 42; pTau, phosphorylated tau; tTau, total tau; MoCA, the Montreal Cognitive Assessment; Week 8, Week 20, and Week 22 in-clinic visits.

\section{Figure 2}

A summary of the SILK experiment. A, lon abundance at $\mathrm{m} / z$ corresponding to the incorporation of one (504), two (505), and three (506) ${ }^{2} \mathrm{H}$ into plasma 24-hydroxycholesterol (24HC). The peak at $m / z 503$ represents the sterol molecular ion. The data for week 0 show the background natural abundance of the 
$24 \mathrm{HC}$ mass isotopomers. B, Plasma $24 \mathrm{HC}$ and body water (inset) enrichment with ${ }^{2} \mathrm{H}$. Dashed line indicate the areas under the curve (AUC), which were used for the estimation of the EFV effect on CYP46A1 activity. W, week of clinic visit. EFV treatment stopped at W 20.

\section{Supplementary Files}

This is a list of supplementary files associated with this preprint. Click to download.

- EFVtrialSupplInfo.pdf 